\title{
Treat Ankylosing Spondylitis with Methazolamide
}

\section{Xiaotian Chang ${ }^{1}$, Xinfeng Yan ${ }^{2}$, Yunzhong Zhang ${ }^{3}$}

1. National Laboratory for Bio-Drugs of Ministry of Health, Provincial Laboratory for Modern Medicine and Technology of Shandong, Research Center for Medicinal Biotechnology of Shandong Academy of Medical Sciences. Jingshi road 18877, Jinan, Shandong, 250062, P. R. China.

2. Orthopedic Surgery Center of Shandong Qianfoshan Hospital, Jinan, Shandong, P. R. China.

3. Department of Rheumatic disease, Occupational Disease Prevention Hospital of Shandong, Jinan, Shandong, P. R. China.

$\triangle$ Corresponding author: Xiaotian Chang, Mail address: Jingshi Road 18877, Jinan, Shandong, 250062. P. R. China. E-mail: changxt@126.com; Tel: +86-531-82919606 ; Fax: +86-531-82951586

(C) Ivyspring International Publisher. This is an open-access article distributed under the terms of the Creative Commons License (http://creativecommons.org/ licenses/by-nc-nd/3.0/). Reproduction is permitted for personal, noncommercial use, provided that the article is in whole, unmodified, and properly cited.

Received: 2011.03.07; Accepted: 2011.06.16; Published: 2011.07.01

\begin{abstract}
Background: Increased bone resorption and new bone information are two characteristics of ankylosing spondylitis (AS). Much evidence has shown that carbonic anhydrase inhibitors can restrain bone resorption. We had detected increased expression of carbonic anhydrase I (CA1) in synovium of patients with AS. This study aimed to evaluate the effectiveness and safety of methazolamide, an anti-carbonic anhydrase drug, for treating patients with AS.

Methods: Two patients, called as $\mathrm{S}$ and $\mathrm{L}$, were diagnosed with active AS based on BASDAI and BASFI assessments, radiographic data and other clinical indices. They took methazolamide tablets at a dose of $25 \mathrm{mg}$ twice every day.

Results: Patient S's BASDAI score fell from 5.4 to 4.4 , while patient L's BASDAI fell from 2.4 to 2. Patient S's BASFI score change from 2.7 to 2.9 , while patient L's BASFI score fell from 1.2 to 0.2 . The ESR values of patient $S$ were considerably reduced, while the ESR value of patient $\mathrm{L}$ remained unchanged and in the normal range. The calcium concentration of patient $S$ decreased from $3.05 \mathrm{mmol} / \mathrm{L}$ to $2.39 \mathrm{mmol} / \mathrm{L}$. The CT evidence indicates that the articular surfaces of the erosive sacroiliac joints became clearer and the area of the calcium deposits began decreased. No significant systemic side effects were observed in either patient.

Conclusions: The above results indicate that methazolamide was effective for active AS. Methazolamide may improve AS symptoms by inhibiting carbonic anhydrase activity during the processes of bone reporption and new bone formation.
\end{abstract}

Key words: ankylosing spondylitis (AS); carbonic anhydrase I (CA1); methazolamide; bone reporption; new bone formation

\section{Introduction}

Ankylosing spondylitis (AS) is a chronic inflammatory rheumatic disease with a prevalence of $0.5-1.9 \%$ (1). Spinal inflammation, the hallmark of AS, causes pain and stiffness that leads to progressive spinal deformity and fusion (1). The disease usually takes a chronic course that is characterized by bone resorption and new bone formation with syndesmophytes and ankylosis (1).

The conventional treatment for AS is mainly based on non-steroidal anti-inflammatory drugs (NSAIDs) and disease modifying anti-rheumatic drugs (DMARDs). Because NSAIDs such as celecoxib 
have a rapid effect on inflammatory symptoms, these drugs are the most commonly used class of medication in treating the pain and stiffness associated with spondyloarthritis. In severe cases of AS, NSAIDs may only be partially effective or the side effects may be too severe to continue their use. In this case, a doctor may prescribe DMARDs such as sulfasalazine to relieve severe symptoms of the disease (2-4). Currently, tumor necrosis factor alpha (TNF-a) blockers are recommended for AS patients with insufficient improvement under conventional treatment. All three of the well-known TNF alpha inhibitors (infliximab, adalimumab and etanercept) have been shown to be highly effective at treating not only the arthritis of the joints but also the spinal arthritis associated with AS (5). Despite the diversity of conventional treatments available for the treatment of AS, no optimal treatment plan has emerged to date (6). The current drugs are also used for rheumatoid arthritis (RA), juvenile RA, psoriatic arthritis and lupus (7). NSAIDs, DMARDs and TNF alpha inhibitors control AS symptoms by inducing an anti-inflammatory response. These drugs do not seem to have much influence on bone resorption and new bone formation in AS (8). For patients with AS, the future of successful treatment lies in the development of new pharmacological interventions capable of altering the fundamental disease course.

Recently, we applied a proteomics approach to identifying novel AS-specific proteins by comparing the expression profiles of synovial membranes from patients with AS, patients with rheumatoid arthritis (RA), and patients with osteoarthritis (OA). Proteins extracted from synovial tissues were separated by 2-D electrophoresis, and the proteins with significantly higher expression in the AS samples were subjected to MALDI-TOF/TOF-MS analysis. The proteomics approach revealed significantly increased expression of carbonic anhydrase I (CA1) in the synovial membranes of patients with AS. Immunohistochemistry and western blotting analysis confirmed the above findings. ELISA detected a higher level of CA1 in synovial fluids from patients with AS than in the RA and OA samples (9). In vitro experiments by other groups indicated that $\mathrm{CA} 1$ catalyzes the generation of $\mathrm{HCO}_{3}{ }^{-}$through hydration of $\mathrm{CO}_{2}$, which then combines with $\mathrm{Ca}^{2+}$ to form a $\mathrm{CaCO}_{3}$ precipitate $(10,11)$. The formation of calcium salt crystals is an essential step during ossification. Over-expression of CA1 in the synovium of AS patients may promote improper calcification during new bone formation, an important feature of AS. Thus, we suggested that carbonic anhydrase inhibitors such as acetazolamide and methazolamide could be effective treatments for AS.
Methazolamide, a sulfonamide derivative, has been used to treat glaucoma for many years and is approved by the US FDA and China FDA. As a carbonic anhydrase inhibitor, methazolamide reduces the rate of fluid formation in the inner eye, presumably by slowing the formation of bicarbonate ions, which causes a subsequent reduction in sodium and fluid transport (12). Much evidence has shown that carbonic anhydrase inhibitors can restrain bone resorption (13-15). In the current study, we treated AS with methazolamide. We enrolled two patients with AS at the active stage in which new bone formation and bone resorption are occurring. Our goal was to assess the effectiveness and safety of methazolamide in patients with AS.

\section{METHODS}

Two patients, referred to as patient $S$ and patient L, were enrolled in this study. The study was approved by The Ethics Committee of Shandong Academy of Medical Sciences. Their symptoms fulfilled the modified New York criteria for AS (16). They had histories of AS for 12 years and 3 years, respectively. The patients were substantially impaired by back pain and spinal immobility. Physical examination revealed the heart, lungs and abdomen to be normal. Their eyes were normal without acute anterior uveitis. Routine laboratory tests were within the normal range except for erythrocyte sedimentation rate (ESR) in patient $S$. The ESRs of patient $S$ and $\mathrm{L}$ were $36 \mathrm{~mm} / \mathrm{h}$ and $12 \mathrm{~mm} / \mathrm{h}$ (reference: $0-20 \mathrm{~mm} / \mathrm{h}$ ), respectively. Analyses to detect RF and anti-cyclic citrullinated peptide (anti-CCP) antibodies were both negative. The calcium concentration of patient $S$ was $3.05 \mathrm{mmol} / \mathrm{L}$, which is higher than normal range (2.1-2.7 mmol/L). We measured disease activity using the Bath AS disease activity index (BASDAI), which is a questionnaire that assesses fatigue; neck, back and hip pain; peripheral joint pain and swelling; discomfort; and severity and duration of morning stiffness $(17,18)$. The BASDAI consists of a 1 through 10 scale ( 1 being no problem and 10 being the worst problem) that is used to assess the five major symptoms of AS. The resulting 0 to 50 score is divided by the five symptoms to give a final $0-10$ BASDAI score. The BASDAI scores of patients $\mathrm{S}$ and L were 5.4 and 2.4, respectively. We also measured physical function of the two patients using BASFI (Bath ankylosing spondylitis functional index). The BASFI is a physical function questionnaire that evaluates dressing, bending, mobility, standing, stairs and full-day activities (19). The higher the BASFI score, the more severely the patient's functioning is limited by their AS ( 1 being no problem and 10 being the worst problem). The 
BASFI scores of patients $\mathrm{S}$ and $\mathrm{L}$ were 2.7 and 1.2, respectively. We examined sacroiliac joints of the patients with computed tomography (CT) and plain $\mathrm{x}$-ray film. The results revealed bilateral sacroiliitis with sclerosis and narrowing of the sacroiliac joints. One sacroiliac joint of patient $\mathrm{S}$ became bony fusion. The articular surfaces were blurred and seemed serrated. Small erosions were observed at the corners of the vertebral bodies in the spine, indicative of early-stage spondylitis. The above observation indicates that patients $S$ and L had active AS at stage II, based on the protocol of Braun et al. (20). Table 1 summarizes the information regarding the two patients. These two patients had previously had unsatisfactory therapy with at least one NSAID. The patients had also been treated with DMARDs such as sulfasalazine and methotrexate. These therapies had been discontinued at least six months before the first use of methazolamide.

This study was designed to examine efficacy and safety of oral methazolamide over a period of 12 weeks. The patients took a 25-mg methazolamide tablet twice every day. The data collected every month included the BASDAI, the BASFI, ESR, immunoglobulin A, immunoglobulin G, immunoglobulin $\mathrm{M}$ and calcium ion concentration. At the end of the treatment, sacroiliac joints of the patients were examined with CT.

Written informed consent was obtained from the patient for publication of this case report and any accompanying images. A copy of the written consent is available for review by the Editor-in-Chief of this journal.

Table 1. Baseline characteristics of the patients with AS

\begin{tabular}{lllllll}
\hline $\begin{array}{l}\text { pa- } \\
\text { tients }\end{array}$ & $\begin{array}{l}\text { gen- } \\
\text { der }\end{array}$ & $\begin{array}{l}\text { age(year } \\
\text { s) }\end{array}$ & $\begin{array}{l}\text { disease } \\
\text { histo- } \\
\text { ry(years) }\end{array}$ & $\begin{array}{l}\text { radio- } \\
\text { graphic } \\
\text { grade }\end{array}$ & $\begin{array}{l}\text { BASDA } \\
1\end{array}$ & $\begin{array}{l}\text { BASF } \\
\text { stage II }\end{array}$ \\
S & man & 28 & 12 & 5.4 & 2.7 \\
L & man & 39 & 3 & stage II & 2.4 & 1.2
\end{tabular}

\section{RESULTS}

After 12 weeks of therapy with methazolamide, patients $S$ and L showed obvious signs of improvement as assessed by the BASDAI and BASFI. The total score BASDAI of patient $S$ fell from 5.4 to 4.4 , whereas the BASDAI of patient $\mathrm{L}$ fell from 2.4 to 1 for the first months, although the BASDAI rebounded to 2 at the third month following the treatment. Obvious im- provements in fatigue, morning stiffness and total back pain were observed in the two patients. However, symptoms of peripheral joint pain and localized tenderness turned to more serious for patient $\mathrm{L}$ at the third month following the treatment. The physical functioning of the two patients also showed improvement. The BASFI of patient $\mathrm{S}$ changed from 2.7 to 2.9 , while that of patient $\mathrm{L}$ fell from 1.2 to 0.2 . Figure 1 and Figure 2 summarize the above results. Both patients increased their physical exercise from the second month of the treatment, when they got improvement with the disease. The ESR value of patient $S$ was considerably reduced, while the value of patient $\mathrm{L}$ did not change and remained in the normal range. The IgM level of patient $S$ declined significantly from $2.32 \mathrm{~g} / \mathrm{L}$ to $1.86 \mathrm{~g} / \mathrm{L}$ after 3 months' treatment. The decline was especially improved at the first month following the treatment. The level of IgM of patient $\mathrm{L}$ did not change significantly and remained in the normal range after the treatment. The IgG levels and the IgA levels were increased for the two patients, although IgG level and the IgA level was considerably declined at the first month of the treatment for patient S. In addition, the calcium concentration of patient $S$ fell from $3.05 \mathrm{mmol} / \mathrm{L}$ to $2.39 \mathrm{mmol} / \mathrm{L}$, while the level of patient $\mathrm{L}$ remained in the normal range. Figure 3 summarizes the above results.
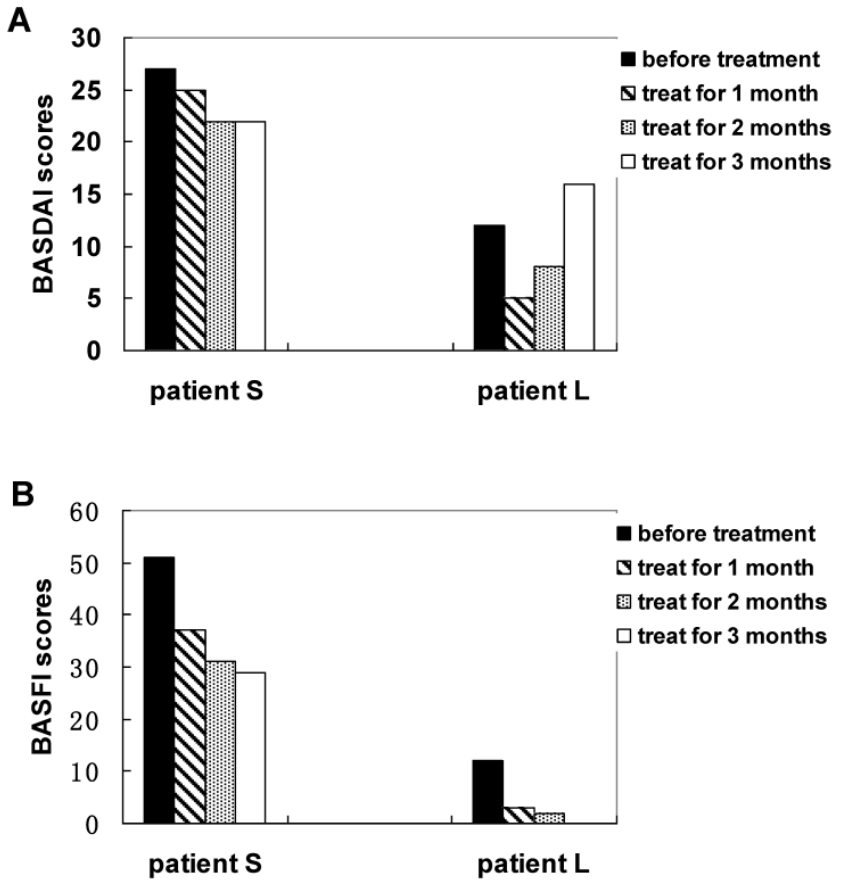

Figure 1. Measuring total scores of BASDAI (A) and BASFI (B) of AS patients with treatment of methazolamide. 

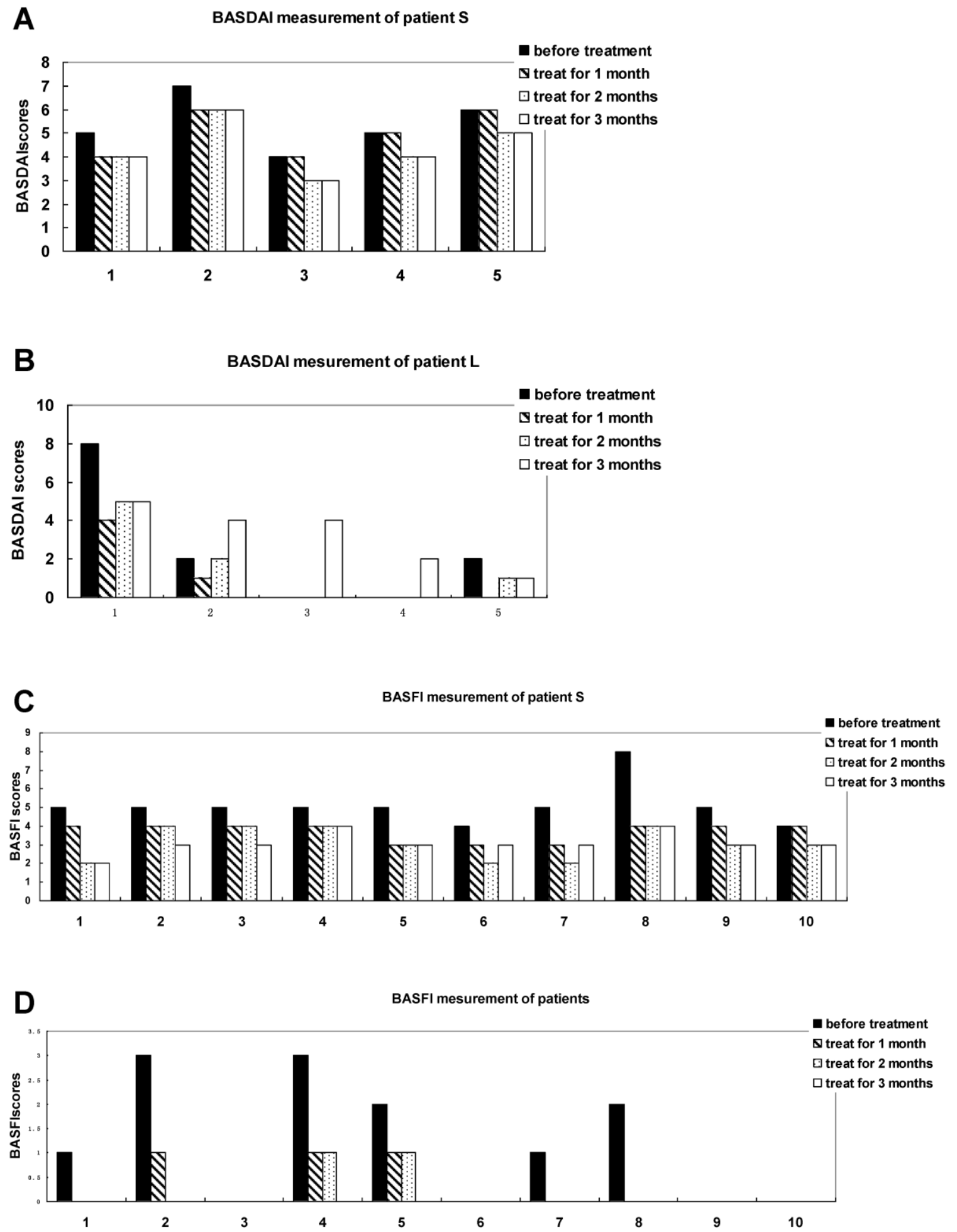

Figure 2. Measuring each index of BASDAI and BASFI of AS patients with treatment of methazolamide. A and B show BASDAI levels of patient $S$ and L, respectively. 1 represents fatigue, 2 spinal pain, 3 peripheral joint pain and swelling, 4 areas of localized tenderness, 5 severities and duration of morning stiffness. C and D show BASFI levels of patient $S$ and $L$, respectively. 1 represents putting on your socks or tights without help or aids, 2 bending from the waist to pick up a pen from the floor without aid, 3 reaching up to a high shelf without help or aids, 4 getting up from an armless chair without your hands or any other help, 5 getting up off the floor without help from lying on your back, 6 standing unsupported for 10 minutes without discomfort, 7 climbing 12-15 steps without using a handrail or walking aid, 8 looking over your shoulder without turning your body, 9 doing physically demanding activities, 10 doing a full day's activities whether it be at home or at work. 

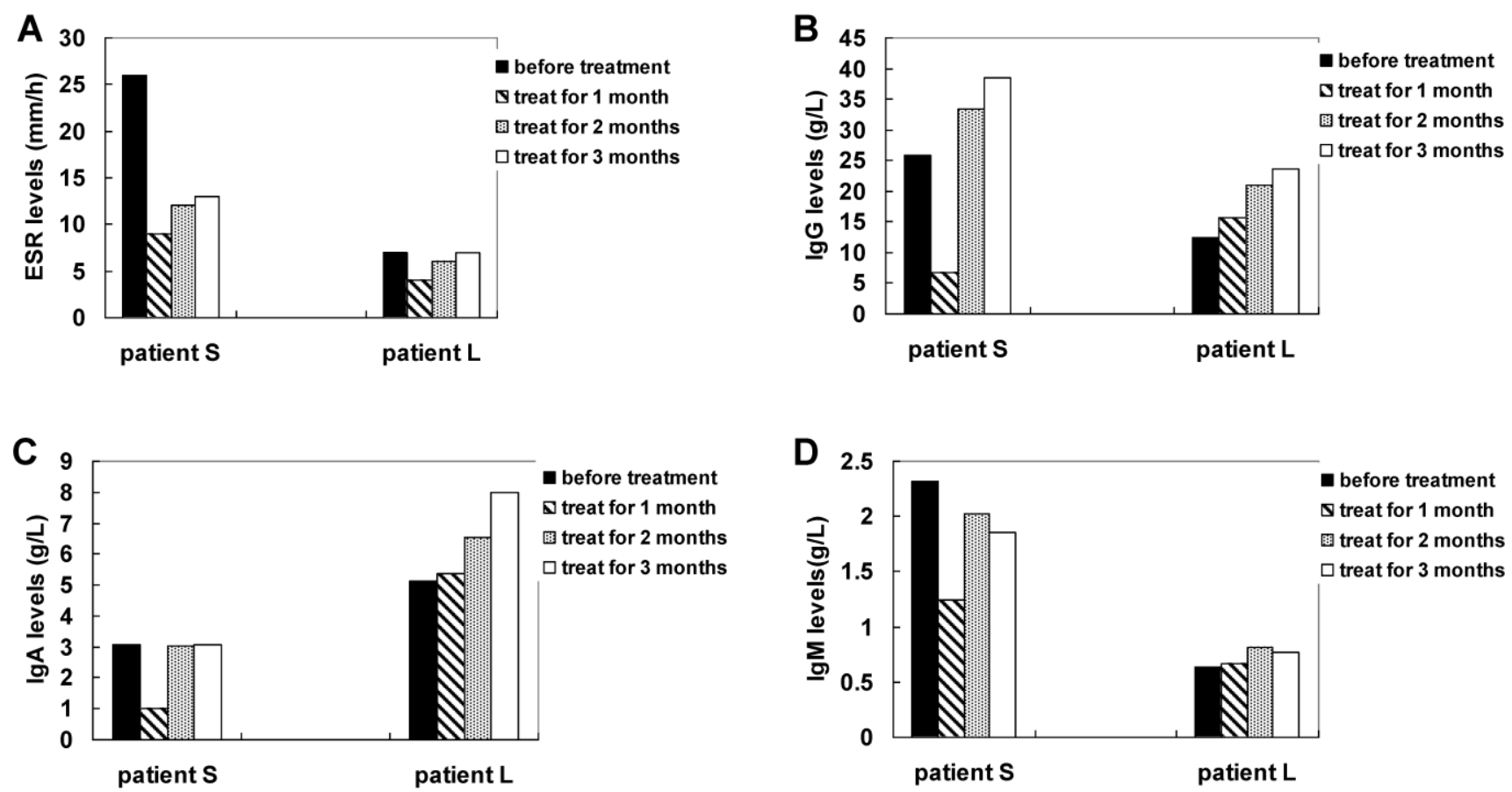

Figure 3. Measuring ESR (A), IgG (B), IgA (C) and IgM (D) levels of AS patients with treatment of methazolamide.
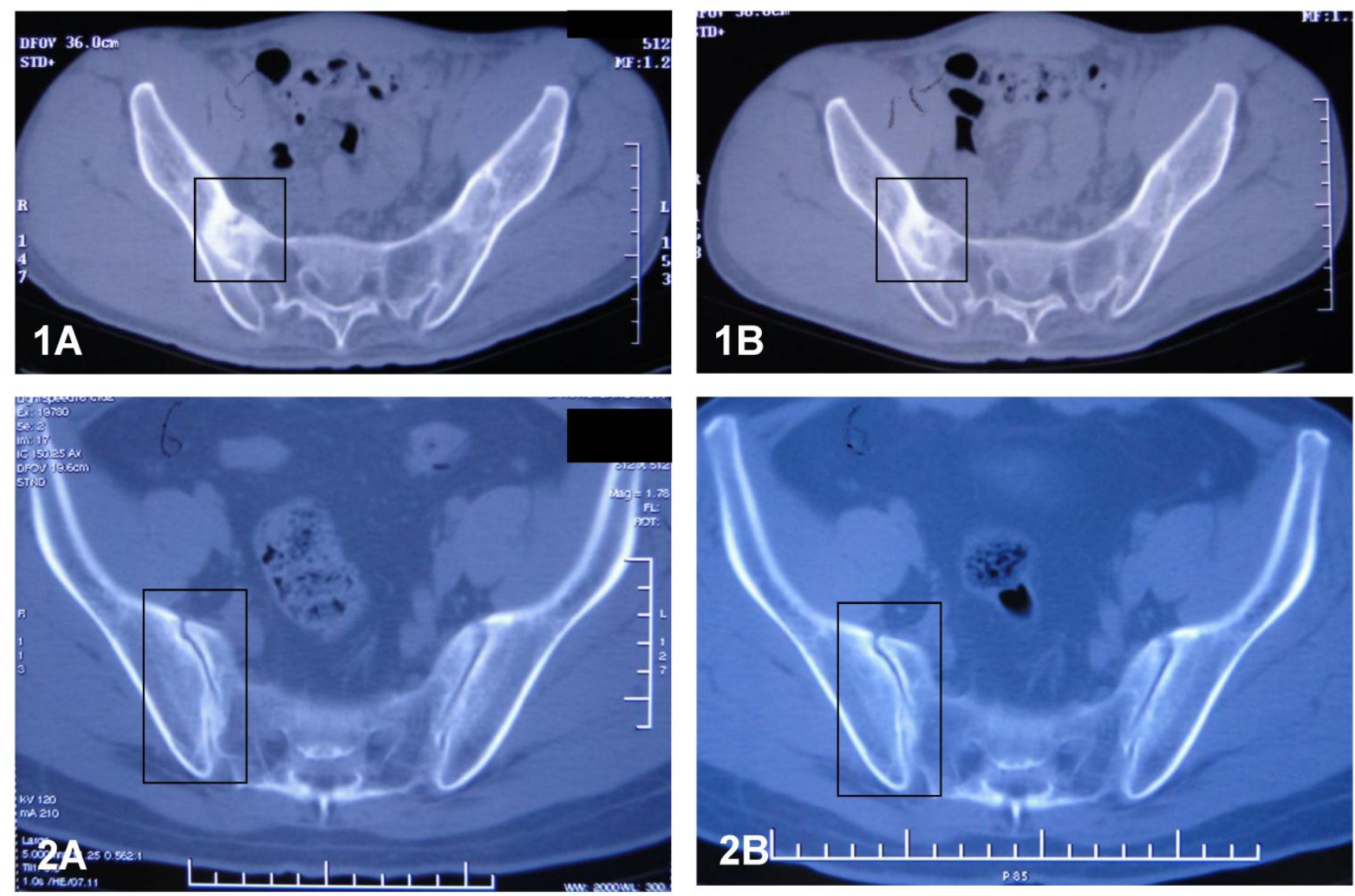

Figure 4. CT results of sacroiliac joints of patient $S(1)$ and patient $L(2)$ before $(A)$ and after (B) the treatment of methazolamide. The evidence indicates that the articular surfaces of the erosive sacroiliac joints became clearer and the area of the calcium deposits began decreased. 
Sacroiliac joints of the patients were examined with CT after the 12 week's treatment. Compared with the observation prior to the treatment, the articular surfaces of the joints became clearer and more distinct than before. The areas of the radioactive material became decreased, indicating increased uptake of calcium deposits in the tissues. The above observation revealed that sacroiliitis, bony erosion and bone formation, hall marks of AS, got improvement during the treatment with methazolamide. Figure 4 shows the CT results.

Significant systemic side effects such as kidney stones, depression, diarrhea and blood abnormalities were not observed in the two patients. Although laboratory tests showed that protein concentrations increased from 0 to $0.15 \mathrm{~g} / \mathrm{L}$ in the urea of patients $\mathrm{S}$ and $L$, this value is still within the normal range. The above results indicate that methazolamide was well-tolerated by the patients after 12 weeks of treatment.

\section{DISCUSSIONS}

In this study, two patients with active AS experienced improvements in fatigue, spinal pain, joint pain and morning stiffness following the treatment of methazolamide. BASDAI and BASFI assessments indicated that they improved with respect to disease activity and physical functioning. In addition, ESR and IgM levels markedly declined in one of the patients, indicating improvements in inflammation and disease activity. Furthermore, CT evidence indicated that the articular surfaces of the erosive sacroiliac joints became clearer and the area of the calcium deposits began decreased, indicating the improvement of sacroiliitis with the two patients. These results demonstrate that methazolamide might be effective for treating patients with AS. On the other hand, the levels of IgG and IgA were increased in the two patients, although the levels were significantly declined in patient $S$ at the first month following the treatment. We cannot explain this alternation of IgG and IgA levels. Mäki-Ikola et al reported that there is no clear correlation between the disease activity and occurrence of $\operatorname{IgG}$ and $\operatorname{Ig}$ A in AS patients (21).

AS is characterized by ossification of the spinal joints and ligaments. Our previous study demonstrated that over-expression of CA1 in the synovium of AS patients may stimulate ossification by accelerating $\mathrm{CaCO}_{3}$ precipitation. Methazolamide belongs to the class of medications called carbonic anhydrase inhibitors. In this study, we found that methazolamide improved the symptom of the patients by global assessment. Thus, we suggest that treatment with methazolamide might restrain the process of new bone formation of $\mathrm{AS}$ by inhibiting $\mathrm{CaCO}_{3}$ precipitation.

Although no previous reports had suggested that methazolamide might be useful for treating AS, evidence has shown that carbonic anhydrase inhibitors can restrain bone resorption. Pierce et al. demonstrated a functional role for carbonic anhydrase in hormone-stimulated bone resorption (13). In an in vitro neonatal mouse calvarial culture system, Hall et al. found that carbonic anhydrase activity enhanced prostaglandin $\mathrm{E}_{2} \mathrm{~s}$ stimulation of bone resorption, indicating that carbonic anhydrase is a necessary component of the osteoclastic bone resorptive mechanism (14). Two years later, that group found that the carbonic anhydrase inhibitor acetazolamide inhibited bone resorption (15). Nolan et al. found that carbonic anhydrase inhibitors, including cetazolamide, ethoxzolamide, methazolamide and dichlorphenamide, reduced paw edema and attenuated the deterioration of the joints of rats with adjuvant arthritis. They suggested that the carbonic anhydrase inhibitors combat arthritis by inhibiting bone resorption (22). The increased bone resorption is a characteristic of AS (23, 24). Thus, we suggest that treatment with methazolamide might also interfere with process of bone resorption of AS. The bone mineral density of patients with AS is reduced $(25,26)$. The calcium concentration of patient $S$ fell from $3.05 \mathrm{mmol} / \mathrm{L}$ to $2.39 \mathrm{mmol} / \mathrm{L}$ after the treatment, supporting the view that methazolamide treatment may interfere with bone resorption in AS.

We report a treatment of active AS with methazolamide. The previous studies reported that methazolamide as the carbonic anhydrase inhibitor can restrain bone resportion and stimulate new bone formation. This finding contributes to our understanding of the causes of AS, and it suggests a potential future for this drug in the clinical therapy. Nevertheless, methazolamide is a treatment option that should be explored in the near future. A larger pilot study would be important to reproduce these findings.

\section{Abbreviations}

AS: ankylosing spondylitis; NSAID: non-steroidal anti-inflammatory drug; DMARD: disease modifying anti-rheumatic drugs; CA1: carbonic anhydrase I; BASDAI: Bath AS disease activity index; BASFI: Bath ankylosing spondylitis functional index; RA: rheumatoid arthritis; OA: osteoarthritis; ESR: erythrocyte sedimentation rate; CT: Computed tomography. 


\section{Acknowledgment}

This study was supported by the National Natural Science Foundation of China (NTFC) (30972720), the National Basic Research Program of China (2010CB529105), the Shandong Taishan Scholarship, and Scientific and Technological Project of Shandong Province (2009ZHZX1A1004).

The authors wish to thank the patients who were accepted to participate in the study. Written consent for publication was obtained from the patients.

\section{Conflict of Interest}

The authors have declared that no conflict of interest exists.

\section{References}

1. Braun J, Sieper J. Ankylosing spondylitis. Lancet, 2007; 369: 1379-1390.

2. van der Horst-Bruinsma IE, Clegg DO, Dijkmans BA. Treatment of ankylosing spondylitis with disease modifying antirheumatic drugs. Clin Exp Rheumatol, 2002; 20 (6 Suppl 28): S67-70.

3. Wanders A, Heijde D, Landewé R, Béhier JM, Calin A, Olivieri I, Zeidler H, Dougados M. Nonsteroidal anti-inflammatory drugs reduce radiographic progression in patients with ankylosing spondylitis. A randomized clinical trial. Arthritis Rheum, 2005; 52: 1756-1765.

4. Ward MM. Prospects for disease modification in ankylosing spondylitis: Do nonsteroidal anti-inflammatory drugs do more than treat symptoms? Arthritis Rheum, 2005; 52:1634-1636.

5. Braun J, Sieper J. Therapy of ankylosing spondylitis and other spondyloarthritides: established medical treatment, anti-TNF-alpha therapy and other novel approaches. Arthritis Res, 2002; 4: 307-321.

6. Dougados M, Dijkmans B, Khan M, Maksymowych W, van der Linden S, Brandt J. Conventional treatments for ankylosing spondylitis. Ann Rheum Dis, 2002; 61 (Suppl 3): iii40-50.

7. Zochling J, van der Heijde D, Burgos-Vargas R, Collantes E, Davis JC Jr, Dijkmans B, Dougados M, Géher P, Inman RD, Khan MA, Kvien TK, Leirisalo-Repo M, Olivieri I, Pavelka K, Sieper J, Stucki G, Sturrock RD, van der Linden S, Wendling D, Böhm H, van Royen BJ, Braun J. Assessment in AS international working group; European League Against Rheumatism ASAS/EULAR recommendations for the management of ankylosing spondylitis. Ann Rheum Dis, 2006; 65: 442-452.

8. Braun J, Sieper J. Treatment of rheumatoid arthritis and ankylosing spondylitis. Clin Exp Rheumatol, 2009; 27(4 Suppl 55): S146-147.

9. Chang X, Han J, Zhao Y, Yan X, Sun S, Cui Y. Increased expression of carbonic anhydrase I in the synovium of patients with ankylosing spondylitis. BMC Musculoskelet Disord, 2010; 11:279.

10. Parissa $\mathrm{M}$, Koorosh $\mathrm{A}$, Nader $\mathrm{M}$. Investigating the Application of Enzyme Carbonic Anhydrase for $\mathrm{CO} 2$ sequestration purposes. Ind Eng Chem Res, 2007:46: 921-926.

11. Ramanan R, Kannan K, Sivanesan SD, Mudliar S, Kaur S, Tripathi AK, Chakrabarti T. Bio-sequestration of carbon dioxide using carbonic anhydrase enzyme purified from Citrobacter freundii. World Journal of Microbiology and Biotechnology, 2009; 25: 981-987.

12. Mincione F, Scozzafava A, Supuran CT. The development of topically acting carbonic anhydrase inhibitors as antiglaucoma agents. Curr Pharm Des, 2008; 14: 649-654.
13. Pierce WMJr, Waite LC. Bone-targeted carbonic anhydrase inhibitors: effect of a proinhibitor on bone resorption in vitro. Proc Soc Exp Biol Med, 1987; 186: 96-102.

14. Hall GE, Kenny AD. Role of carbonic anhydrase in bone resorption induced by prostaglandin E2 in vitro. Pharmacology, 1985; 30: 339-347.

15. Hall GE, Kenny AD. Role of carbonic anhydrase in bone resorption: effect of acetazolamide on basal and parathyroid hormone-induced bone metabolism. Calcif Tissue Int, 1987; 40: 212-218.

16. van der Linden S, Valkenburg HA, Cats A. Evaluation of diagnostic criteria for ankylosing spondylitis: a proposal for modification of the New York criteria. Arthritis Rheum, 1984; 27: 361-368.

17. Garrett S, Jenkinson T, Kennedy LG, Whitelock H, Gaisford P, Calin A. A new approach to defining disease status in ankylosing spondylitis: the Bath Ankylosing Spondylitis Disease Activity Index. J Rheumatol, 1994; 21: 2286-2291.

18. Calin A, Nakache JP, Gueguen A, Zeidler H, Mielants H, Dougados M. Defining disease activity in ankylosing spondylitis: is a combination of variables (Bath Ankylosing Spondylitis Disease Activity Index) an appropriate instrument? J Rheumatol, 1999; 38: 878-882.

19. Calin A, Garrett S, Whitelock H, Kennedy LG, O'Hea J, Mallorie $\mathrm{P}$, Jenkinson T. A new approach to defining functional ability in ankylosing spondylitis: the development of the Bath Ankylosing Spondylitis Functional Index. J Rheumatol, 1994; 21: 2281-2285.

20. Braun J, van der Heijde D, Dougados M, Emery P, Khan MA, Sieper J, van der Linden S. Staging of patients with ankylosing spondylitis: a preliminary proposal. Ann Rheum Dis, 2002; 61(Suppl. 3): iii19-23.

21. Mäki-Ikola O, Lehtinen $K$, Granfors $K$, Vainionpää R, Toivanen P. Bacterial antibodies in ankylosing spondylitis. Clin Exp Immunol, 1991; 84: 472-475.

22. Nolan JC, Gathright CE, Radvany CH, Barrett RJ, Sancilio LF. Carbonic anhydrase inhibitors are antiarthritic in the rat. Pharmacol Res, 1991; 24: 377-383.

23. Schett $G$. Bone formation versus bone resorption in ankylosing spondylitis. Adv Exp Med Biol, 2009; 649:114-121.

24. Grisar J, Bernecker PM, Aringer M, Redlich K, Sedlak M, Wolozcszuk W, Spitzauer S, Grampp S, Kainberger F, Ebner W, Smolen JS, Pietschmann P. Ankylosing spondylitis, psoriatic arthritis, and reactive arthritis show increased bone resorption, but differ with regard to bone formation. J Rheumatol, 2002; 29: 1430-1436.

25. Gratacós J, Collado A, Pons F, Osaba M, Sanmartí R, Roqué M, Larrosa M, Múñoz-Gómez J. Significant loss of bone mass in patients with early, active ankylosing spondylitis: a followup study. Arthritis Rheum, 1999; 42: 2319-2324.

26. Bronson WD, Walker SE, Hillman LS, Keisler D, Hoyt T, Allen $\mathrm{SH}$. Bone mineral density and biochemical markers of bone metabolism in ankylosing spondylitis. J Rheumatol, 1998; 25: 929-935. 